\title{
Effect of Acyclovir Treatment of Primary Genital Herpes on the Antibody Response to Herpes Simplex Virus
}

Rhoda L. Ashley and Lawrence Corey

Departments of Laboratory Medicine, Microbiology and

Immunology, University of Washington, and the Children's

Orthopedic Hospital, Seatte, Washington 98105

bstract. Sera from patients with first episode primary genital herpes infections who were treated with the antiviral drug acyclovir were studied to determine the effect of therapy on the immune response to herpes simplex virus (HSV) glycoproteins and polypeptides. $63 \mathrm{pa-}$ tients were evaluated, 35 patients received acyclovir: 11 intravenously, 12 orally, and 12 topically, while 28 received placebo. Topical application of acyclovir had no effect on the immune response to HSV infection. However, both oral and intravenous acyclovir were associated with later development of antibodies to two glycoproteins (of 80,000 and $60,000 \mathrm{~mol} w t$ [IIg80 and $\mathrm{gD}$, respectively]) and one nonglycosylated polypeptide of $66,000 \mathrm{~mol} \mathrm{wt}$ (vp66). Antibody to IIg80 was present in convalescent phase serum in $13 / 23$ systemic acyclovir recipients vs. $18 / 19$ placebo recipients $(P=0.01)$ and antibody to $\mathrm{gD}$ was detected in $8 / 23$ oral or intravenous acyclovir recipients vs. $11 / 19$ placebo recipients $(P=0.06)$. The mean time to seroconversion to $\operatorname{Ig} 80(39.0 \mathrm{~d})$ and $\mathrm{gD}(55.5 \mathrm{~d})$ was significantly longer for systemic acyclovir recipients than for the placebo controls, 23.4 and $18.5 \mathrm{~d}$, respectively ( $P<0.05$ for each comparison). 7 (30\%) of 23 systemic acyclovir recipients compared with $100 \%$ of the placebo recipients had antibody to vp 66 by $30 \mathrm{~d}$ after onset of the primary episode $(P<0.001)$.

Subsequent untreated recurrences of genital herpes were associated with seroconversion to $\mathrm{gD}$, IIg80, and vp66. Patients who lacked antibody to both $\mathrm{gD}$ and vp66 in sera taken before their first clinical recurrence of disease experienced a longer duration of the recurrent episode

Address reprint requests to Dr. Ashley, Children's Orthopedic Hospital. 1983.

Received for publication 12 April 1983 and in revised form 17 October

J. Clin. Invest.

(c) The American Society for Clinical Investigation, Inc.

0021-9738/84/03/0681/08 $\$ 1.00$

Volume 73, March 1984, 681-688
(10.8 d) than those who possessed antibody to both vp66 and $\mathrm{gD}(6.3 \mathrm{~d})(P<0.05)$. In addition, the mean duration of lesions, number of lesions, and mean lesion area were greater in patients who lacked antibody to vp66 but had anti $\mathrm{gD}$, as compared with those who had anti-p66 but lacked anti-gD; suggesting that antibody to vp 66 correlated more closely with subsequent disease severity than did antibody to $\mathrm{gD}$.

Acyclovir therapy appears to influence the frequency and time of development of antibody to a number of different HSV-specific polypeptides. Further studies of the effects of antiviral therapies on the immune response to these proteins may help clarify the role of these polypeptides in the pathogenesis of disease.

\section{Introduction}

Previous studies evaluating host immune responses in primary genital herpes simplex virus (HSV) ${ }^{1}$ infection have shown that antibody responses to viral glycoproteins with molecular weights of 130,000 and 115,000 , and the nonglycosylated major nucleocapsid protein of $148,000 \mathrm{~mol}$ wt can be detected within the first $10 \mathrm{~d}$ of disease in all patients with primary first episode genital HSV-2 infection $(1,2)$. Antibodies to glycoproteins of 60,000 and $80,000 \mathrm{~mol} w \mathrm{w}$ and to a nonglycosylated polypeptide of 66,000 mol wt subsequently appear by $21-28 \mathrm{~d}$ after onset of symptoms in sera of untreated patients with primary genital HSV-2 infection $(1,2)$.

The antiviral agent acyclovir has been shown to be a clinically effective treatment for primary first episode genital herpes in immunocompetent patients (3-8). In clinical trials, intravenous, oral, and topical acyclovir decreased the duration of viral shedding by 85,80 , and $50 \%$, respectively, as compared with similarly

1. Abbreviations used in this paper: HSV, herpes simplex virus; HSV2 glycoproteins and their molecular weights $(\mathrm{pgD}, 50,000 ; \mathrm{gD}, 60,000$; IIg80, 80,000; gE, 70,000-80,000; gF, 80,000; gAB, 115,000; IIg130, $130,000)$; FET, Fisher's exact test; nonglycosylated proteins and their molecular weights (vp66, 66,000; vp88, 88,000; vp148, 148,000). 
followed placebo recipients $(4,5,8)$. In the trials of intravenous and oral acyclovir, neutralizing antibody titers to HSV-2 in convalescent phase sera were lower in acyclovir-treated as compared with placebo-treated patients $(5,8)$. In contrast, antiHSV-2 neutralizing antibody titers in convalescent-phase sera of patients using topical acyclovir recipients were similar to the neutralizing-antibody titers in placebo recipients $(3,4)$. To analyze the effect of systemic acyclovir treatment on the humoral response to HSV-specific polypeptides, we evaluated sequential sera from 63 patients with primary HSV-2 genital infections who were enrolled in trials of intravenous, oral, and topical acyclovir.

\section{Methods}

Patient population. Patients were entered into placebo-controlled trials of intravenous, oral, and topical acyclovir at the University of Washington Herpes Research Clinic located at the Harborview Medical Center Seattle, WA. All patients presented to the clinic within $7 \mathrm{~d}$ after developing genital lesions, all had HSV-2 isolated from their genital lesions, and none had evidence of antibody to either HSV-1 or HSV-2 in their acutephase sera (i.e., were experiencing "primary first episode" genital HSV2 infection). During their acute episode, patients were followed with serial genital exams, and lesions were sampled for viral cultures every other day until healing occurred $(4,5,8)$. Patients were then seen at 3$6 \mathrm{wk}$ intervals and during subsequent clinical recurrences. Sera were drawn at the first clinic visit, posttherapy, day 21 , at $6 \mathrm{wk}$, and during each recurrence.

Serology. Neutralizing antibodies to HSV were measured by microneutralization using serial dilutions of sera from 1:4 to 1:128. The titer of antibody was the highest dilution of sera inhibiting $50 \%$ of the viral input as determined by the Reed-Meunch formula $(3,9)$. In calculating the mean titer of neutralizing antibody, titers of $<1: 4$ were arbitrarily given a value of $1: 2$

Radioimmunoprecipitation of virus-specified polypeptides. Patients' sera were reacted with $\left[{ }^{35}\right.$ S $]$ methionine-labeled antigen that was prepared from cytoplasmic extracts of infected human embryonic tonsil cells. Briefly, confluent monolayers were incubated $2 \mathrm{~h}$ with HSV-2 (strain 333) at a multiplicity of infection of 1.0 plaque-forming unit per cell. Cells were washed and incubated an additional $5 \mathrm{~h}$ in methionine-free minimal essential media before $20 \mu \mathrm{Ci} / \mathrm{ml}$ of $\left[{ }^{35} \mathrm{~S}\right]$ methionine $(1,100$ $\mathrm{Ci} / \mathrm{mmol}$; New England Nuclear, Boston, MA) was added. Viral glycoproteins were radiolabeled by addition of $10 \mu \mathrm{Ci} / \mathrm{ml}$ of $\left[{ }^{14} \mathrm{C}\right]$ glucosamine $(54.2 \mathrm{Ci} / \mathrm{mmol}$; New England Nuclear) at $7 \mathrm{~h}$ postinfection. $16 \mathrm{~h}$ later cells radiolabeled with ${ }^{35} \mathrm{~S}$ or ${ }^{14} \mathrm{C}$ were washed and suspended in lysis buffer (10 mM Tris, pH 8.0; 0.1 mM EDTA, $0.1 \mathrm{M}$ $\mathrm{NaCl}, 1 \%$ Nonidet $\mathrm{P}-40 ; 1 \%$ sodium deoxycholate) for $30 \mathrm{~min}$ on ice. The cytoplasmic fraction was obtained by low-speed centrifugation and insoluble proteins were pelleted at $430,000 \mathrm{~g}$ for $30 \mathrm{~min}$. The resulting cytoplasmic extract was diluted $1: 40$ and reacted with human sera that was diluted 1:4 in Tris $0.01 \mathrm{M}, \mathrm{pH}$ 8.0. Antigen-antibody complexes were collected on SPA-sepharose beads (Sigma Chemical Co., St. Louis, MO), washed, denatured, and run on $9 \%$ polyacrylamide gels in $1 \%$ sodium dodecyl sulfate. Radioimmunoprecipitated proteins and glycoproteins were visualized by fluorography with $1 \mathrm{M}$ sodium salicylate and exposed to Kodak XAR film (Eastman Kodak Co., Rochester, NY) for 2-10 d. Each serum sample was reacted with HSV-2 and with mockinfected cell antigen. Each antigen preparation was tested against seronegative human sera and was preadsorbed to that sera, if necessary.
Statistical methods. Comparison between groups was performed by Fisher's exact test (FET), chi square analysis, or $t$ test, as specified.

Viral glycoproteins. Recent reports have indicated that the HSV-1 glycoprotein at $130,000 \mathrm{~mol} \mathrm{wt}(\mathrm{gC})$ and the HSV-2 $80,000 \mathrm{~mol}$ wt glycoprotein designated $\mathrm{gF}(10)$ are related immunologically (11) and map to colinear regions of the respective genomes. Further, the reported molecular weight of $\mathrm{gF}(10,11)$ is similar to that of HSV-2 $\mathrm{gE}(70,000$ $80,000 \mathrm{~mol} \mathrm{wt}$ ) (12). A glycoprotein of $50,000 \mathrm{~mol} \mathrm{wt}$ is immunoprecipitated by monoclonal antibody to $\mathrm{gD}$ (our unpublished data) and has been suggested as a precursor of $\mathrm{gD}$ (13). For the purpose of reporting our results, we have used the following nomenclature for HSV-2 glycoproteins which are immunoprecipitated in our system by human sera: $\operatorname{IIg} 130(\mathrm{~mol} \mathrm{wt}=130,000)$, gAB $(115,000)(14,15)$, IIg80 $(80,000), \mathrm{gD}$ $(60,000)$, and $\mathrm{pgD}(50,000)$ (Fig. 1).

\section{Results}

63 patients ( 43 women and 20 men) with primary genital HSV2 infection were evaluated. 35 received acyclovir: 11 intravenously $(5 \mathrm{mg} / \mathrm{kg}$ every $8 \mathrm{~h}$ for $5 \mathrm{~d}), 12$ orally ( $200 \mathrm{mg}$ five times daily for $10 \mathrm{~d}$ ), and 12 by topical application of $5 \%$ acyclovir in polyethylene glycol to external genital lesions six times daily for $7 \mathrm{~d}$. Of the 28 placebo-treated patients, 10 were enrolled in the intravenous trial and nine each were enrolled in the oral and topical acyclovir trials. The mean duration of viral shedding from the onset of lesions to the last positive viral culture was $7.0 \mathrm{~d}$ in those treated with intravenous acyclovir, $5.5 \mathrm{~d}$ in those treated with oral acyclovir, and $7.0 \mathrm{~d}$ in patients treated with

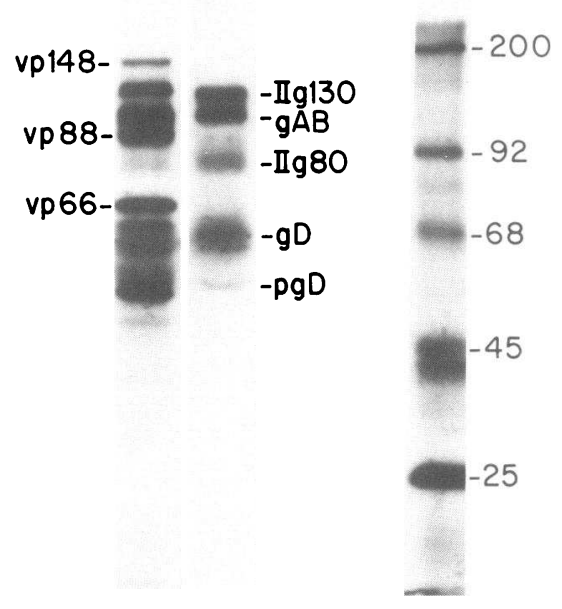

Figure 1. Immunoprecipitation of HSV-2 glycoproteins and polypeptides. HSV-2 antigens radiolabeled with $\left[{ }^{35}\right.$ S $]$ methionine (left lane) or $\left[{ }^{14} \mathrm{C}\right]$ glucosamine (right lane) were precipitated by serum antibody from a patient with recurrent genital herpes due to HSV-2. Immunoprecipitated proteins were electrophoresed into polyacrylamide gels and radiolabeled bands were visualized by fluorography and exposure to $\mathrm{x}$-ray film. ${ }^{14} \mathrm{C}$-labeled proteins of known molecular weight are shown at the far right with their molecular weight designations in kilodaltons. Lanes were run on the same gel but cut out and rearranged for presentation. 
topical acyclovir. Placebo-treated patients shed HSV from genital lesions for a mean of $15.0 \mathrm{~d}$. The mean time from the onset of lesions to the first serum sample was $3.7 \mathrm{~d}$ in acyclovir- and $4.0 \mathrm{~d}$ in placebo-treated patients (range 1-7 d) in all three studies. The mean time from last sexual exposure to the acute serum sample was $7.3 \mathrm{~d}$ for both acyclovir and placebo recipients.

Antibodies to viral glycoproteins and polypeptides in acutephase sera. While all patients lacked HSV-neutralizing antibody in their first serum sample (acute phase), 60 of 63 patients had antibody detected by radioimmunoprecipitation to the glycoproteins IIg130 and gAB (Table I and Fig. 2, lanes A and D) and the major nucleocapsid polypeptide of $148,000 \mathrm{~mol} \mathrm{wt}$ (vp148) (Fig. 2). 48 patients (63.2\%) had antibodies to a nonglycosylated viral polypeptide of $88,000 \mathrm{~mol} \mathrm{wt}(\mathrm{vp} 88)$, while $7(11.1 \%)$ had antibody to another nonglycosylated polypeptide of 66,000 mol wt (vp66). 13 patients had antibody to IIg80, and 4 of the 63 patients $(6.3 \%)$ had antibody to $\mathrm{gD}$ in acutephase sera. No significant differences in the frequency of antibody were noted in acute-phase sera in patients randomized to acyclovir or placebo treatment (Table I) or between patients enrolled in the intravenous, oral, or topical studies.

Neutralizing antibodies in convalescent-phase sera. All 28 placebo and 31 of 35 acyclovir-treated patients developed antiHSV-2-neutralizing antibody in sera drawn 14-30 d after the onset of symptoms (convalescent-phase sera). The mean titers of neutralizing antibody to HSV-1 and HSV-2 were 9.7 and 10.6, respectively, in intravenous acyclovir recipients; 14.7 and 16.7, respectively, in oral acyclovir patients, and 16.8 and 28.8 respectively, in topical acyclovir recipients. The mean titers of neutralizing antibody to HSV-1 and HSV-2 in convalescentphase sera in the 28 placebo-treated patients were 18.7 and 19.1, respectively. The mean neutralizing antibody titer to HSV-2 in convalescent-phase sera was 19.5 in placebo recipients enrolled in the oral and intravenous trials as compared with 11.2 in patients with first episode primary genital HSV-2 infection treated with oral or intravenous acyclovir $(P<0.05 ; t$ test).

Antibodies to viral glycoproteins and polypeptides in convalescent-phase sera. All 63 patients had demonstrable antibody

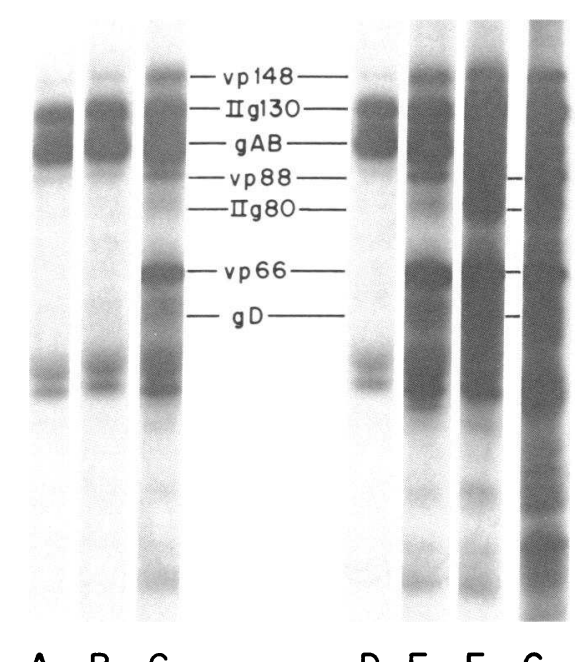
A B C
$D E F \quad G$

Figure 2. Electrophoretic profiles of $\left[{ }^{35} \mathrm{~S}\right]$ methionine labeled HSV-2 proteins precipitated by sequential sera from a patient receiving oral acyclovir (lanes $A, B, C$ ) or oral placebo (lanes $D, E, F$ ). Sera were drawn on day 5 (lanes $A, D$ ) day 28 (lanes $B, E$ ) and days 80 and 66 (lanes $C$ and $F$, respectively) after onset of symptoms. The acyclovir patient had his first clinical recurrence at day 76 . The placebo patient recurred at day 60 . The HSV-2 antigen preparation used in these radioimmunoprecipitations is shown in lane G. Note that while the acute-phase sera are similar with respect to the proteins precipitated, convalescent-phase sera from day 28 from the acyclovir patient and from the placebo patient differ. The placebo serum has antibodies to IIg80, vp66, and gD. Antibody to IIg130, gAB, vp148, and vp88 was demonstrable in all sera.

to vp148, IIg130, and gAB in their convalascent-phase sera (Table I, Fig. 2, lanes B and E). 56 (89\%) of 63 patients developed antibody to vp88 by $28 \mathrm{~d}$ after onset of symptoms (Table I).

The frequency of detectable antibody to IIg80 and vp66 in day 28 sera differed between acyclovir and placebo recipients. 24 acyclovir recipients $(68.6 \%)$ vs. 25 placebo recipients $(89.3 \%)$

Table I. Frequency of Antibody to HSV-2 Glycoproteins and Polypeptides in Acyclovir (ACV)- and Placebo-treated Patients

\begin{tabular}{|c|c|c|c|c|c|c|}
\hline \multirow[b]{2}{*}{ Protein } & \multicolumn{2}{|c|}{ Acute phase sera } & \multicolumn{2}{|c|}{ Day 28 sera } & \multicolumn{2}{|c|}{ Follow-up sera* } \\
\hline & $\operatorname{ACV}(n=35)$ & Placebo $(n=28)$ & $\operatorname{ACV}(n=35)$ & Placebo $(n=28)$ & $\operatorname{ACV}(n=35)$ & Placebo $(n=28)$ \\
\hline vp148 & 34 & 26 & 35 & 28 & 35 & 28 \\
\hline IIg130 & 34 & 26 & 35 & 28 & 35 & 28 \\
\hline gAB & 34 & 26 & 35 & 28 & 35 & 28 \\
\hline vp88 & 25 & 23 & 30 & 26 & 32 & 28 \\
\hline IIg80 & 9 & 4 & 24 & 25 & 33 & 26 \\
\hline vp66 & 3 & 4 & 18 & 28 & 33 & 28 \\
\hline gD & 2 & 2 & 15 & 17 & 26 & 20 \\
\hline
\end{tabular}

$n=$ number of patients in whom antibody to the designated protein was detected in serum sample. * Sera were drawn within $10 \mathrm{~d}$ of the first clinical recurrence or between 35 and $90 \mathrm{~d}$ of onset of the first episode from those patients who did not have clinical recurrences. 


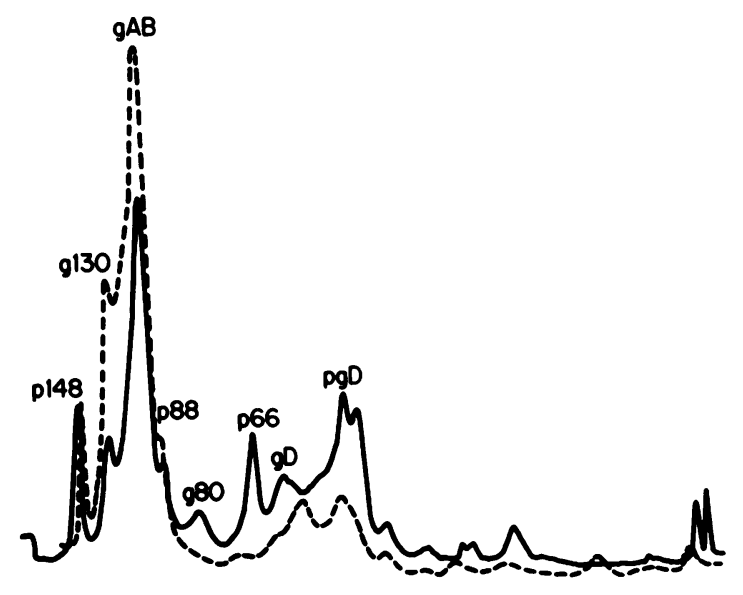

Figure 3. Densitometer scans of fluorograms of $\left[{ }^{35} S\right]$ methionine labeled HSV-2 proteins precipitated by convalescent phase sera from an oral acyclovir-treated patient (- - ) and from an oral placebotreated patient $(-$ While no difference in levels of precipitated vp148 (p148) and vp88 (p88) are apparent, levels of precipitated IIg1 30 (g130) and gAB are higher in the acyclovir patient's profile. Lower levels of precipitated $\mathrm{gD}$ and $\mathrm{pgD}$ and lack of precipitated IIg80 (g80) and vp66 (p66) are apparent in the profile generated using the acyclovir patient's serum. Note that in comparing tracings of other acyclovir- or placebo-treated patients' profiles, relative levels of precipitated vp148, IIg130, gAB, and vp88 were not consistently different nor were levels of precipitated proteins of $<60,000 \mathrm{~mol} \mathrm{wt}$. The only consistent differences between acyclovir and placebo patients' convalescent sera were in the frequency or levels of precipitated IIg80, vp66, and gD (Tables I-III).

had antibody to IIg80 ( $P=0.05$; chi square), while all of the placebo patients vs. $18(62.9 \%)$ acyclovir recipients had antibody to vp66 $(P<0.001$; chi square $)$.
In addition to the difference in frequency of seroconversion to IIg80 and vp66 between acyclovir and placebo-treated patients, densitometry tracings revealed that the amounts of IIg80 and gD immunoprecipitated by convalescent-phase sera were less in the acyclovir-treated group (Fig. 3). While the frequency of seroconversion to $\mathrm{gD}$ by day 28 was similar in acyclovir (42.9\%) and placebo recipients $(60.7 \%)$ (Table II), the amount of $\mathrm{gD}$ immunoprecipitated by seropositive sera from acyclovir patients was consistently less than the levels of $\mathrm{gD}$ precipitated by placebo patients' sera (Fig. 3). Relative levels of immunoprecipitated vp148, IIg130, gAB, and vp88 varied between individuals (2) and were not consistently different between acyclovir and placebo-treated patients.

Antibodies to IIg80, gD, and vp66 in convalescent-phase sera of systemic acyclovir recipients. The differences in the frequency and amount of precipitating antibody to IIg80, gD, and vp66 in convalescent-phase sera between acyclovir and placebo recipients were seen only in intravenous or oral acyclovir recipients and not those treated with the topical preparation. Antibody to IIg80 was detected in convalescent-phase sera in 7 of 12 oral acyclovir and in 6 of 11 intravenous acyclovir recipients, compared with 18 of the 19 placebo-treated patients enrolled in these two studies $(P=0.01$, FET $)$. The mean time required for seroconversion to IIg80 was 43.0 and $35.5 \mathrm{~d}$ in intravenous and oral acyclovir recipients vs. 29.7 and $18.6 \mathrm{~d}$ in their placebotreated counterparts $(P<0.05, t$ test). In contrast to systemic acyclovir-treated patients, antibody to IIg80 was demonstrated by $28 \mathrm{~d}$ after onset of lesions in 11 of 12 topical acyclovir recipients compared with 7 of the 9 placebo-treated patients enrolled in this study. The mean time to seroconversion was also similar between topical acyclovir and placebo recipients; 22.0 and $22.4 \mathrm{~d}$, respectively.

Antibody to $\mathrm{gD}$ was detected in convalescent-phase serum of $17(61 \%)$ placebo recipients compared with 4 of 11 patients

Table II. Effect of Acyclovir (ACV) on Development of Antibody to $\mathrm{gD}$

\begin{tabular}{|c|c|c|c|c|}
\hline Treatment group & $\begin{array}{l}\text { No. who developed antibody } \\
\text { to } \mathrm{gD} \text { by } 30 \mathrm{~d} \text { into illness }\end{array}$ & $\begin{array}{l}\text { No. who developed antibody } \\
\text { to } \mathrm{gD} \text { in follow-up sera* }\end{array}$ & $\begin{array}{l}\text { Mean time to } \\
\text { seroconversion }\end{array}$ & Range \\
\hline & & & $d$ & $d$ \\
\hline IV-ACV $n=11$ & $4(36 \%)$ & 4 & $\begin{array}{l}76.8 \\
(P<0.05) \ddagger\end{array}$ & $11-210$ \\
\hline IV-placebo $n=10$ & $6(60 \%)$ & 1 & 18.8 & $7-34$ \\
\hline Oral-AV $n=12$ & $4(33 \%)$ & 5 & $\begin{array}{l}55.2 \\
(P<0.05) \ddagger\end{array}$ & $11-137$ \\
\hline Oral placebo $n=9$ & $5(56 \%)$ & 1 & 18.2 & $10-34$ \\
\hline Topical ACV $n=12$ & $7(58 \%)$ & 2 & 16.2 & $4-37$ \\
\hline Topical placebo $n=9$ & $6(67 \%)$ & 1 & 22.8 & $6-35$ \\
\hline
\end{tabular}

* Sera were drawn within $10 \mathrm{~d}$ of the first clinical recurrence or within $90 \mathrm{~d}$ of onset of the first episode from those patients who did not have clinical recurrences. $¥$ The $t$ test. 
treated with intravenous acyclovir, 4 of 12 treated with oral acyclovir, and 7 of 12 treated with topical acyclovir (Table II) ( $P=0.06$; FET for comparison between oral and intravenous acyclovir-treated and placebo-treated patients). The mean time to seroconversion to $\mathrm{gD}$ was $76.8 \mathrm{~d}$ and $55.2 \mathrm{~d}$ in intravenous and oral acyclovir recipients compared with 18.8 days and 18.2 $\mathrm{d}$ in their placebo-treated counterparts $(P<0.05$ for comparison between oral and intravenous acyclovir and placebo-treated patients (Table II).

The frequency and time course of development of antibody to vp66 was also affected by systemic acyclovir treatment. While all placebo recipients had detectable antibody to vp66 in convalescent-phase sera, only 4 of 11 intravenous acyclovir recipients and 3 of 12 oral acyclovir recipients had detectable antibody to vp66 in these sera $(P<0.001$, FET) (Table III). Antibody to vp66 was detected in convalescent-phase sera in 11 of the 12 patients treated with topical acyclovir.

To determine whether the lack of antibodies to vp66, IIg80, or $\mathrm{gD}$ was due to an artifact such as degradation of these polypeptides by factors in the sera of acyclovir recipients, supernatants from the radioimmunoprecipitates were reacted with fresh serum that had previously been shown to immunoprecipitate vp66, IIg80, and gD. In all cases tested, all three polypeptides could be detected in the resulting precipitates. In addition, to evaluate whether these patients had antibodies to these polypeptides that were not bound by protein $A$, the experiment was repeated using sheep antihuman Fab as the secondary system. The results confirmed the lack of detectable antibody to vp66, IIg80, and $\mathrm{gD}$ in the sera in question.

Effect of recurrence on antibody development. Almost all the patients who lacked antibody to IIg80, gD, and/or vp66 in convalescent sera seroconverted to these polypeptides during followup; usually in association with their first untreated clinical recurrence of genital herpes (Table I). For example, 10 (9 acyclovir and 1 placebo) of the 14 patients lacking antibody to IIg80 in their day 28 sera developed antibody to IIg80 during followup. 5 of the 9 acyclovir recipients seroconverted to IIg80 within $10 \mathrm{~d}$ of the first clinical recurrence. The remaining five patients seroconverted within $90 \mathrm{~d}$ of the first episode without apparent association with a recurrent episode of disease. 14 of the 31 patients ( 11 acyclovir and three placebo recipients) who lacked antibody to $\mathrm{gD}$ in their day 28 sera seroconverted during followup. 9 of these 14 patients, all acyclovir recipients, seroconverted within $10 \mathrm{~d}$ of the first clinical recurrence.

15 of the 17 acyclovir-treated patients who lacked antibody to vp66 in their day 28 sera seroconverted to vp66 during followup. Seroconversion to vp 66 was associated with the first clinical recurrence of genital herpes in 14 of these 15 patients. The 15th patient had antibody to vp66 detected in sera taken at a routine visit $111 \mathrm{~d}$ after her primary episode. Two patients (both intravenous acyclovir recipients) did not develop anti-vp66 during the course of follow-up. One did not develop anti-vp66 in sera $210 \mathrm{~d}$ after onset of her illness, despite a single symptomatic recurrence of genital herpes at day 103 . The other patient had
Table III. Effect of Acyclovir (ACV) on Development of Antibody to vp66

\begin{tabular}{|c|c|c|c|}
\hline Treatment group & $\begin{array}{l}\text { No. who developed } \\
\text { anti-vp66 in } \\
\text { convalescent sera }\end{array}$ & $\begin{array}{l}\text { No. who developed } \\
\text { anti-vp66 after } \\
\text { untreated recurrence }\end{array}$ & $\begin{array}{l}\text { Mean time to } \\
\text { seroconversion } \\
\text { to vp66 }\end{array}$ \\
\hline $\begin{array}{l}\text { IV-ACV } \\
\quad(n=11)\end{array}$ & 4 & 5 & $\begin{array}{l}91.6( \pm 24.2) \\
P<0.01^{*}\end{array}$ \\
\hline $\begin{array}{l}\text { Placebo ACV } \\
(n=10)\end{array}$ & 10 & NA $\ddagger$ & $16.0( \pm 2.8)$ \\
\hline $\begin{array}{l}\text { Oral ACV } \\
\quad(n=12)\end{array}$ & 3 & 8 & $\begin{array}{l}74.6( \pm 13.6) \\
P<0.01^{*}\end{array}$ \\
\hline $\begin{array}{l}\text { Oral placebo } \\
\quad(n=9)\end{array}$ & 9 & NAł & $16.1( \pm 2.8)$ \\
\hline $\begin{array}{c}\text { Topical ACV } \\
(n=12)\end{array}$ & 11 & 1 & $23.3( \pm 2.5)$ \\
\hline $\begin{array}{l}\text { Topical placebo } \\
\quad(n=9)\end{array}$ & 9 & NA $\ddagger$ & $23.0( \pm 3.1)$ \\
\hline
\end{tabular}

* The $t$ test.

¥ NA, not applicable; all placebo-treated patients had anti-vp66 before their first clinical recurrence.

no reported recurrences and no evidence of anti-vp66 before being lost to follow-up $57 \mathrm{~d}$ after enrollment into the study.

The 93\% seroconversion rate to vp66 in association with an overt recurrence of disease was higher than the 64 and $50 \%$ seroconversion rates with a recurrence seen with $\mathrm{gD}$ and $\mathrm{IIg80}$ $(P=0.08$ and 0.03 (FET), respectively, for comparison between vp66 and $\mathrm{gD}$ and IIg80).

Association of antibody to $\mathrm{vp} 66$ and $\mathrm{gD}$ and severity of the first clinical recurrence. To evaluate the association between the presence of antibodies to IIg80, gD, and vp66 and disease course, we compared the severity and times to first clinical recurrence in patients who lacked one or more of these antibodies to those who possessed antibodies to these polypeptides in convalescentphase sera. The median time to first clinical recurrence $(83.5$ d) was not affected by the presence or absence of demonstrable antibodies to vp66, gD, and/or IIg80 in day 28 sera.

Information on the clinical manifestations of the first untreated clinical recurrence of disease was available on 47 of the patients who recurred during the follow-up period. Of these 47 patients, 12 lacked antibody to both gD and vp66 in sera taken before the recurrence, 9 lacked gD but had anti-vp66, 3 possessed antibody to $\mathrm{gD}$ but lacked anti-vp66 and 23 had detectable amounts of antibody to both $\mathrm{gD}$ and vp 66 before the first clinical recurrence.

The mean duration of lesions during the first clinical recurrence was $10.8 \mathrm{~d}$ in the 12 patients who lacked antibody to $\mathrm{gD}$ and vp66 compared with $6.3 \mathrm{~d}$ in those who were seropositive for both these polypeptides $(0.01<P<0.02, t$ test $)$ (Table IV). 
Table IV. Relationship between the Presence of Antibody to gD and vp66 in Sera Taken before the First Clinical Recurrence and Clinical Severity of Disease

\begin{tabular}{|c|c|c|c|c|}
\hline Present & $\begin{array}{l}\text { A: both anti } g D \\
\text { anti vp66 } \\
(n=23)\end{array}$ & $\begin{array}{l}\text { B: anti-gD absent } \\
\text { anti vp66 present } \\
(n=9)\end{array}$ & $\begin{array}{l}\text { C: anti-gD present } \\
\text { anti vp66 absent } \\
(n=3)\end{array}$ & $\begin{array}{l}\text { D: both anti } g D \\
\& \text { anti vp66 absent } \\
(n=12)\end{array}$ \\
\hline Mean duration of lesions* & $\begin{array}{c}6.3 \\
(3.3)\end{array}$ & $\begin{array}{c}8.0 \S \\
(3.4)\end{array}$ & $\begin{array}{l}14.3 \\
(4.9)\end{array}$ & $\begin{array}{l}10.7^{\prime \prime} \\
(6.8)\end{array}$ \\
\hline Mean number of lesions $\ddagger$ & $\begin{array}{c}2.9 \\
(2.2)\end{array}$ & $\begin{array}{c}3.0 \S \\
(1.9)\end{array}$ & $\begin{array}{c}5.8 \\
(1.1)\end{array}$ & $\begin{array}{c}6.1 \\
(9.7)\end{array}$ \\
\hline Mean lesion area $\left(\mathrm{mm}^{2}\right)^{*}$ & $\begin{array}{c}17.4 \\
(18.6)\end{array}$ & $\begin{array}{l}16.5 \pi \\
(25)\end{array}$ & $\begin{array}{l}52.0 \\
(6.1)\end{array}$ & $\begin{array}{c}37.9 \\
(44)\end{array}$ \\
\hline
\end{tabular}

Standard deviation is given in parentheses. ${ }^{*} P<0.01$ (The $t$ test for comparison between groups A \& $\mathrm{C}$ ). $¥ 0.02<P<0.05$ (The $t$ test for comparison between groups A \& C). $\$ 0.02<P<0.05$ (The $t$ test for comparison between groups B \& C). I $P=0.08$ (The $t$ test for comparison between groups B \& C). " $0.01<P<0.02$ (The $t$ test for comparison between groups A and D).

The mean number of lesions (6.1) and mean lesion area $(36.0$ $\mathrm{mm}^{2}$ ) also tended to be larger in patients who lacked both $\mathrm{gD}$ and vp66 in sera before the recurrence as compared with those who possessed both $\mathrm{gD}$ and vp66 (2.9 lesions and $17.44 \mathrm{~mm}^{2}$ ) but these differences were not statistically significant.

The mean duration of the first clinical recurrence was 11.5 d in 15 patients who lacked antibody to vp66 in sera taken before the recurrence compared with $6.8 \mathrm{~d}$ for the 32 patients who possessed detectable anti-vp66 in their sera $(0.02<P<0.05$ $t$ test). Similarly, the mean number of lesions (6.0) and mean area of lesions $\left(39.8 \mathrm{~mm}^{2}\right)$ was greater in the 15 patients who lacked antibody to vp66 as compared with the 32 patients who possessed antibody to vp66 before the recurrence (2.9 lesions and $\left.17.2 \mathrm{~mm}^{2}\right)(P<0.05 t$ test $)$. The clinical manifestations of the recurrence were similar in those who were seropositive or seronegative for $\mathrm{gD}$ before the recurrent episode. The mean duration of lesions $(9.6 \mathrm{~d})$, mean number of lesions (4.8), and mean lesion area $\left(28.1 \mathrm{~mm}^{2}\right)$ were similar for the 21 patients who lacked antibody to $\mathrm{gD}$ before their first clinical recurrence as compared with the 26 patients who possessed antibody to gD in sera before the recurrence (7.2 d, 3.2 lesions, and 21.4 $\mathrm{mm}^{2}$, respectively, $P>0.05$ ). The clinical severity of disease was also similar between the 9 patients who lacked only gD as compared with the 23 who were seropositive for both $\mathrm{gD}$ and vp66. The mean duration of lesions, mean number of lesions and mean lesion area were also greater in the 3 patients who lacked antibody to vp66 but had gD-specific antibody than in those who either had antibody to both these polypeptides or to vp66 alone (Table IV).

No apparent association between presence or absence of antibody to IIg80 and severity of the first clinical recurrence was noted. However, as lack of antibody to vp66 or $\mathrm{gD}$ and IIg80 were not related, the number of patients for subset analysis was small. For example, 10 of the 17 patients who lacked antibody to vp66 in convalescent sera had demonstrable antibody to IIg80. Similarly, of the $\mathbf{3 0}$ patients who lacked antibody to gD, 18 had antibody to IIg80. Presence or absence of antibody to IIg80 did not appear to be a covariable with antibodies to vp66 and/or $\mathrm{gD}$ in severity of the recurrence.

\section{Discussion}

Our study indicates that systemic acyclovir treatment of first episode primary genital HSV-2 infection influences the subsequent development of antibodies to HSV-specified polypeptides. Patients who were treated with oral or intravenous acyclovir within $7 \mathrm{~d}$ of onset of their first episode of primary genital HSV demonstrated (a) lower neutralizing antibody titers to HSV-2 in convalescent-phase sera, $(b)$ lower frequency and delayed seroconversion to $\mathrm{gD}$ and IIg80, and $(c)$ decreased frequency of seroconversion to vp66. Acyclovir treatment may also affect the frequency of time of seroconversion to other minor viral proteins. However, the variable response of patients to minor proteins precluded drawing conclusions from the populations studied. In contrast, topical acyclovir application to external genital lesions was not associated with alteration of the neutralizing antibody response or to any change in frequency or amount of precipitating antibodies directed to HSV-specified polypeptides.

Convalescent-phase sera of patients treated with oral or intravenous acyclovir had lower neutralizing antibody titers and decreased frequency of precipitating antibodies to IIg80 and vp66. Decreased levels of precipitating antibody to $\mathrm{gD}$ were apparent in these sera. However, the frequency and levels of precipitating antibodies to IIg 130 and gAB appeared to be unaffected by acyclovir therapy. Numerous reports have indicated that virion surface glycoproteins are associated with neutralization (16-18). In particular, mouse monoclonal antibodies to gAB have been shown to neutralize infectivity of HSV-1 (16) and HSV-2 (17), while antibodies to HSV-1 gC can neutralize 
HSV-1 infectivity $(19,20)$. Mouse monoclonal antibodies to HSV-1 gD have also been shown to have neutralizing activity in vitro (19) and in vivo (20). Our findings using human sera suggest that optimal neutralization of $\mathrm{HSV}$ in humans may require participation of antibodies directed against more than one surface glycoprotein and/or even the presence of antibodies to nonglycosylated polypeptides; a hypothesis that could be addressed with direct functional assays of antibodies to these proteins.

The mechanism by which systemic acyclovir influences the subsequent development of HSV-specific polypeptides is not clear. The difference in the immune response between systemic and topically treated acyclovir recipients may be due to the greater effect of systemic acyclovir on the duration of viral shedding. In addition, topical acyclovir therapy does not affect the duration of viral shedding at mucosal sites such as the cervix, throat, and urethra; sites infected in $>90 \%$ of persons with primary first episodes of genital herpes. Follow-up of oral and intravenous acyclovir-treated patients who did not seroconvert to gD, IIg80, or vp66 after their primary infection revealed that almost all subsequently developed antibodies to these viral polypeptides. $93 \%$ of those who subsequently seroconverted to vp 66 , $64 \%$ of those who subsequently seroconverted to $\mathrm{gD}$, and $50 \%$ of those who subsequently seroconverted to IIg80 did so in association with an untreated recurrence of disease. It should be remembered that asymptomatic shedding of virus from the cervix, vulva, or urethra does occur, is of short duration, and would not have resulted in the patient reporting to our clinic. $(21,22)$. The late seroconversions to these polypeptides not associated with overt recurrences may have been in response to asymptomatic episodes of viral shedding. Whether host immune responses to viral polypeptides; in particular vp66, IIg80, and $\mathrm{gD}$ differ between asymptomatic vs. symptomatic periods of disease will require further study.

The high frequency of seroconversion to $\mathrm{vp} 66$ and $\mathrm{gD}$ in conjunction with the first untreated recurrence of genital herpes does, however, suggest that the delayed development of antibody to these polypeptides after the first episode of genital herpes is related to the effect of acyclovir on viral replication rather than to a failure of the host-immune response to these specific polypeptides. Systemic acyclovir treatment markedly shortens the duration of viral shedding during the primary episode $(5,8)$. Virus may be present in inadequate amounts or for too short a period of time for immune stimulation by these viral polypeptides. Alternatively, acyclovir treatment may produce noninfectious particles lacking these polypeptides or may cause an alteration in the antigenicity of these viral polypeptides. While acyclovir has been shown to produce noninfectious defective particles in vitro, a similar effect in vivo has not been shown.

Evaluation of the severity of the subsequent clinical recurrences after systemic acyclovir therapy indicated that patients who lacked antibody to both $\mathrm{gD}$ and vp66 had a significantly longer duration of lesions than those who had antibodies to both these proteins in sera taken before the recurrence. While the number of patients who lacked only one of these two antibodies was small, patients who were seronegative to vp66 but seropositive to $\mathrm{gD}$ tended to have more lesions, larger lesion areas, and a longer duration of lesions as compared with those who lacked only antibody to gD. Thus, while acyclovir therapy affects a variety of viral polypeptides, these data suggest that antibody to vp66, in particular, may be an important marker of clinical severity of infection. Development of specific quantitative assays for antibodies to vp66 and other HSV polypeptides should allow further evaluation as to the role they play in the clinical expression of symptomatic and/or asymptomatic genital HSV infections.

While systemic acyclovir therapy and its apparent effect on antibodies to viral-specified polypeptides appears to affect the first untreated clinical recurrence of genital herpes, our data should not be construed to discourage the use of systemic acyclovir treatment for primary first episode genital herpes. The clinical benefit of systemic acyclovir therapy in primary disease does, in our opinion, offset the slight increase in severity of the first subsequent recurrence of disease, seen in the $40-60 \%$ of systemic acyclovir-treated patients who have delayed seroconversion to $\mathrm{gD}$ and/or vp66 $(4,8)$. Detailed monitoring of the effect of systemic acyclovir therapy on the long-term natural history of the clinical and immunologic responses of patients with genital herpes is likely to provide valuable insights into host and virion factors that influence disease expression and/ or severity.

\section{Acknowledgments}

We gratefully acknowledge the technical assistance of Michael Schick. This work was supported in part by National Institutes of Health (NIH) grants AI-20381 and AI-14495 and NIH Training Grant AI07149 .

\section{References}

1. Zweerink, H. J., and L. Corey. 1982. The diagnosis and treatment of genital herpes. J. Am. Med. Assoc. 248:1041-1049.

2. Ashley, R. L., K. Fife, and L. Corey. 1982. Specific humoral immunity in patients receiving acyclovir treatment for primary genital herpes virus (HSV) infections. Clin Res. 30:361A. (Abstr.)

3. Corey, L., M. E. Nahmias, M. E. Guinan, J. K. Benedetti, C. W. Critchlow, and K. K. Holmes. 1982. A trial of topical acyclovir in genital herpes simplex virus infections. $N$. Engl. J. Med. 306:1313-1319.

4. Corey, L., J. K. Benedetti, C. Critchlow, M. R. Remington, C. A. Winter, A. L. Fahnlander, K. Y. Smith, D. L. Salter, R. E. Keeney, L. G. Davis, M. A. Hintz, J. D. Connor, and K. K. Holmes. 1982. Double blind controlled trial of topical acyclovir in genital herpes simplex virus infections: the Seattle experience. Am. J. Med. 73(1A):326-334.

5. Corey, L., K. H. Fife, J. K. Benedetti, C. Winter, A. Fahnlander, J. D. Connor, M. A. Hintz, and K. K. Holmes. 1983. Intravenous acyclovir for the treatment of primary genital herpes. Ann. Intern. Med. 98:914-921.

6. Mindel, A., M. W. Adler, S. Sutherland, and A. P. Fiddian. 1982. 
Intravenous acyclovir treatment for primary genital herpes. Lancet. I:697700.

7. Nilson, A. E., T. Assen, A. M. Halsos, B. R. Kinge, E. A. L. Tjotta, K. Wikstrom, and A. P. Fiddian. 1982. Efficacy of oral acyclovir in the treatment of initial and recurrent genital herpes. Lancet. II:571573.

8. Mertz, G. J., R. Reichman, R. Dolin, D. D. Richman, M. Oxman, K. Large, D. Tyrrell, J. Portnoy, and L. Corey. 1982. Double-blind placebo-controlled trial of oral acyclovir for first episode genital herpes. 22nd Interscience Conference on Antimicrobial Agents and Chemotherapy (ICAAC), Miami Beach, Florida.

9. Rawls, W. E., K. Iwamoto, E. Adam, and J. L. Melnick. 1970. Measurement of antibodies to Herpesvirus types 1 and 2 in human sera. J. Immunol. 104:599-606.

10. Balachandrian, N., D. Harnish, R. A. Killington, S. Bacchetti, and W. E. Rawls. 1981. Monoclonal antibodies to two glycoproteins of herpes simplex virus type 2. J. Virol. 39:438-446.

11. Para, M. F., K. M. Zezulak, A. J. Conley, M. Weinberger, K. Snitzer, and P. G. Spear. 1983. Use of monoclonal antibodies against two 75,000-molecular weight glycoproteins specified by herpes simplex virus type 2 in glycoprotein identification and gene mapping. J. Virol. 45:1223-1227.

12. Pava, M. F., L. Goldstein, and P. G. Spear. 1982. Similarities and differences in the Fc-binding glycoprotein (gE) of herpes simplex virus types 1 and 2 and tentative mapping of the viral gene for this glycoprotein. J. Virol. 41:137-144.

13. Eisenberg, R. J., M. Ponce de Leon, and G. H. Cohen. 1980. Comparative structural analysis of glycoprotein $\mathrm{gD}$ of herpes simplex virus 1 and 2. J. Virol. 35:428-435.

14. Balachandrian, J., D. Harnish, W. E. Rawls, and S. Bacchetti.
1982. Glycoproteins of herpes simplex virus type 2 as defined by monoclonal antibodies. J. Virol. 44:344-355.

15. Eberle, R., and R. J. Courtney. 1980. gA and gB glycoproteins of herpes simplex virus type 1: two forms of a single polypeptide. $J$. Virol. 36:665-675.

16. Sarmiento, M., M. Haffey, and P. G. Spear. 1979. Membrane proteins specified by herpes simplex viruses III. Role of glycoproteins VP7 (B2) in virion activity. J. Virol. 29:1149-1158.

17. Eberle, R., and R. J. Courtney. 1980. Preparation and characterization of specific antisera to individual glycoprotein antigens comprising the major glycoprotein region of herpes simplex virus type $1 . J$. Virol. 35:902-917.

18. Powell, K. L., A. Buchan, C. Sim, and D. H. Watson. 1974 Type-specific protein in herpes simplex virus envelope reacts with neutralizing antibiotics. Nature (Lond.). 249:360-361.

19. Pereira, L., T. Klassen, and J. R. Barringer. 1980. Type-common and type-specific monoclonal antibody to herpes simplex virus type 1 . Infect. Immun. 29:724-732.

20. Dix, R. D., L. Pereira, and J. R. Barringer. 1981. Use of monoclonal antibody directed against herpes simplex virus glycoproteins to protect mice against acute virus-induced neurological disease. Infect. Immun. 34:192-199.

21. Rattray, M. D., L. Corey, W. C. Reeves, L. A. Vontver, and K. K. Holmes. 1978. Recurrent genital herpes among women: symptomatic vs. asymptomatic viral shedding. Br. J. Vener. Dis. 54:262265.

22. Vontver, L. A., D. E. Hickok, Z. Brown, L. Read, and L. Corey. 1982. Recurrent genital herpes simplex virus infection in pregnancy: infant outcome and frequency of asymptomatic recurrences. Am. J. Obstet. Gynecol. 142:75-84. 